\title{
Incidencia de la inteligencia emocional en el proceso de aprendizaje
}

\section{María Graciela Calle Márquez ${ }^{1}$, Nahyr Remolina De Cleves ${ }^{1}$, Bertha Marlene Velásquez Burgos ${ }^{1}$}

1. Docente investigadora de la Facultad de Ciencias de la Salud, Programa de Bacteriología y Laboratorio Clínico, línea de investigación Desarrollo educativo, pedagógico y curricular, Universidad Colegio Mayor de Cundinamarca, Bogotá D.C., Colombia

Correspondencia: bemar5@yahoo.es

Recibido: 15/ 03 / 2011 - Aceptado: 07 / 06 / 2011

\section{Resumen}

El presente artículo da a conocer algunos aspectos relacionados con la morfofisiología del cerebro límbico o emocional y los componentes químicos que intervienen en las emociones de los estudiantes; se exponen los conceptos de inteligencia emocional propuestos por diferentes expertos y se definen las competencias emocionales que deben desarrollar los estudiantes desde la perspectiva de las autoras del trabajo, docentes universitarias. De igual modo, se presenta la importancia de la inteligencia emocional en el aula y se proponen estrategias que facilitan su desarrollo y aprovechamiento para el logro del aprendizaje de los estudiantes.

Palabras clave: cerebro límbico o emocional, neurotransmisores, inteligencia emocional, competencias emocionales, estrategias pedagógicas.

\section{Abstract \\ Incidence of emotional intelligence in the learning process}

This article unveils some aspects about morphophysiology limbic or emotional brain and the chemical components involved in the emotions of students, introduces the concepts of emotional intelligence proposed by different experts and emotional competencies are defined to be developed students from the perspective of the authors of the work, university teachers. Similarly, we present the importance of emotional intelligence in the classroom and suggests strategies to facilitate their development and use for learning achievement of students. Keywords: limbic or emotional brain, neurotransmitters, emotional intelligence, emotional skills, teaching strategies.

\section{Introducción}

La sociedad contemporánea denominada de la información y del conocimiento evidencia complejidad en los ámbitos industrial y tecnológico, así como en la tendencia permanente a la mundialización y globalización económica, política, social y cultural; esto exige la utilización de habilidades y competencias tanto personales, como sociales y profesionales para lograr eficacia y eficiencia en el desempeńo frente a los cambios continuos que exigen las necesidades actuales.

Por las anteriores razones, se comprende que los mecanismos que utilizamos para manejar de manera adecuada los problemas de la cotidianidad no son 
suficientes y, por tanto, se hace necesario prestar atención no sólo a la dimensión cognitiva, sino también a la dimensión emocional de la persona, la cual debe ser educada para que las emociones y los sentimientos afloren convirtiéndose en apoyo, estímulo y guía para la vida.

En esta perspectiva, la teoría del cerebro triuno expuesta por Sperry (1) y Mclean (2), ofrece una amplia ilustración sobre la importancia del tema para los docentes. De acuerdo con estos autores, el cerebro humano está conformado por tres estructuras cerebrales: la neocorteza, (racional), el sistema límbico (emocional) y el reptiliano (patrones de comportamiento), que actúan de manera integrada aunque cada estructura da cuenta de sus respectivas especificidades y funciones.

Por otra parte, Ned Herrmann (3) en la teoría del cerebro total propone un modelo que integra la neocorteza (hemisferio izquierdo y derecho) con el sistema límbico. Concibe esta integración como una totalidad orgánica dividida en cuatro cuadrantes, a partir de cuyas interacciones se puede lograr un estudio más amplio y completo de la operatividad del cerebro, sus implicaciones para la creatividad y el aprendizaje. Cada uno de los cuadrantes realiza funciones diferenciadas; así, el cuadrante cortical izquierdo se caracteriza por un estilo de pensamiento racional, lógico, crítico y basado en hechos concretos. Por su parte, el cuadrante inferior izquierdo, denominado límbico izquierdo, se caracteriza por un estilo de pensamiento secuencial, organizado y planificado; el cuadrante inferior derecho o límbico derecho, se caracteriza por un estilo de pensamiento emocional, sensorial, musical, interpersonal. Finalmente, el cuadrante superior derecho o cortical derecho se caracteriza por un estilo de pensamiento conceptual, holístico, integrador, creativo, espacial y metafórico (4).

En este orden de ideas, el informe Delors (5) hace referencia a los cambios de estilos de vida que vive el mundo contemporáneo y con el fin de dar respuesta a las tensiones que se manifiestan en los grupos sociales plantea los cuatro pilares de la educación referidos al mundo emocional: aprender a conocer, que significa dominar los instrumentos del conocimiento, para favorecer el placer de la comprensión y descubrimiento de los factores emocionales ligados al aprendizaje. Aprender a hacer, que se relaciona con adquirir la formación para lograr un desempeño idóneo en el quehacer profesional $y$, a la vez, desarrollar competencias personales que se manifiestan en el trabajo en equipo, toma de decisiones, estímulo de la sinergia para interactuar de manera grupal; según se observa, estas competencias forman parte de la inteligencia emocional. Aprender a convivir y participar en proyectos comunes; es éste uno de los mayores retos del presente milenio, puesto que la convivencia nos induce a descubrir lo que tenemos en común, a aceptar las diferencias y comprender que somos interdependientes. Mas, para descubrir al otro(a) es necesario descubrirnos a nosotros mismos. Aprender a ser, hace alusión al desarrollo máximo y posible de la persona, a su proceso de autorrealización plena; esta referencia a la educación integral justifica por sí misma la necesidad imperativa de formar con inteligencia emocional.

El informe, como se muestra, subraya el papel de las emociones y hace énfasis en la exigencia de educar esta dimensión del ser humano paralelamente con la dimensión cognitiva, compromiso en que debe centrarse el sistema educativo. Para ello, se requiere que la educación contemple la apertura hacia las nuevas propuestas de cambio desde el punto de vista del desarrollo de la inteligencia emocional, para solucionar los problemas de la crisis social y afrontar los diversos desafíos que presenta el entorno. Lo anterior exige una concienciación del docente para que se apreste a revisar el currículo e incluya las dimensiones referidas a la formación de la inteligencia emocional de la persona.

De acuerdo con lo expuesto, el objeto del presente artículo es proponer una reflexión crítica en torno de la incidencia de la inteligencia emocional en los procesos de aprendizaje de los estudiantes, con la intención de promover las nuevas ideas sobre el tema en las instituciones educativas. Si la misión educativa refleja interés por el desarrollo emocional de aquellos, es necesario, por una parte, conocer el marco teórico y, por otra, crear una cultura organizacional que suscite el avance emocional de los estudiantes, docentes y comunidad educativa en general.

En el presente trabajo se exponen aspectos básicos relacionados con la neuroanatomía de las emociones, 
es decir, su estructura biofísica y los componentes químicos que inciden en las manifestaciones emocionales de los estudiantes; así mismo, se dan a conocer los conceptos de inteligencia emocional propuestos por investigadores y estudiosos del tema, así como las competencias emocionales que han de desarrollar los estudiantes. De igual modo, se hace referencia a la importancia e implicaciones de la inteligencia emocional en el aula; se visualiza, además, las estrategias que propician su desarrollo y por ende el aprendizaje de los estudiantes. A continuación, se hace énfasis en el por qué y para qué de la propuesta enunciada en el recorrido del artículo partiendo de una realidad plena de exigencias e imperativos a los cuales es preciso dar una respuesta desde la neuropedagogía, que contempla al cerebro como centro y motor del proceso de aprendizaje.

\section{La neuroanatomía de las emociones}

Los neurocientíficos en la actualidad afirman que el cerebro humano está conformado por tres cerebros: el cerebro instintivo o reptiliano, el cerebro emocional o límbico y el cognitivo o neocorteza.

El sistema límbico o parte emocional del cerebro, se encuentra alojado dentro de los hemisferios cerebrales; incluye el hipocampo donde se produce el aprendizaje emocional y se almacenan los recuerdos emocionales; la amígdala, considerada el centro del control emocional del cerebro; el tálamo, cuya función es procesar la información de los sentidos y convertirla en acción, es decir, dar respuesta emocional a las sensaciones; el hipotálamo interviene en la conducta emocional y la actividad endocrina; el sistema endocrino y el sistema nervioso autónomo. En la persona, aquéllos actúan como centros de la afectividad donde se procesan las distintas emociones y se experimentan alegrías, penas, temores y angustias entre otras. $(1,2)$

Como se puede observar existen diferentes centros o vías de la emoción; sin embargo, la amígdala parece ser la más implicada, en ella se distinguen de doce a quince regiones emocionales distintas de las cuales sólo se han identificado dos y son las vinculadas con el miedo; otras emociones pueden estar relacionadas con otras áreas. De acuerdo con Jensen (6) la amígdala, innegablemente, ejerce gran influencia en nuestro córtex, hay mas entradas a partir de la amígdala al córtex que en sentido contrario; aún así la información fluye en los dos sentidos; en este aspecto, se entiende que el lado emocional es el que nos anima y no el lógico.

La amígdala reacciona con tal rapidez que la respuesta se da antes de llegar al cortex, según Goleman (7):

una señal visual va de la retina al tálamo [...] después el cortex emite la respuesta [...]. Si esta respuesta es emocional, una señal se dirige a la amígdala para activar los centros emocionales, pero una pequeña porción de la señal original va directamente desde el tálamo a la amígdala por una vía más corta, permitiendo una respuesta más rápida (aunque ciertamente también más imprecisa). De este modo, la amígdala puede desencadenar una respuesta antes de que los centros corticales hayan comprendido completamente lo que está ocurriendo.

Con lo anterior se deduce que la mente emocional es más rápida que la mente racional; esta se activa con rapidez sin detenerse a analizar las consecuencias de una acción, sigue una lógica asociativa y un pensamiento categórico. Sin embargo, se precisa hacer énfasis en que el sistema límbico está en constante interacción con la corteza cerebral. Es así como una transmisión de señales de alta velocidad facilita el trabajo conjunto del sistema límbico y el neocórtex, ello explica el control que ejercemos sobre nuestras emociones.

De otra parte, es evidente el papel especial que juegan los lóbulos prefrontales y frontales, en la asimilación neocortical de las emociones. Como directores de las emociones, los lóbulos ejecutan dos importantes funciones: moderan nuestras reacciones emocionales, frenando las señales del cerebro límbico y desarrollan programas concretos de actuación en situaciones emocionales determinadas, en tanto que la amígdala del sistema límbico acude en auxilio de situaciones emocionales extremas, el lóbulo prefrontal coordina nuestras emociones. Es así como el cero emocional, según Eduardo Punset (8), es el punto en el cual se forman los circuitos neuronales, que determinan cómo afrontarán ciertas situaciones niños y niñas en el aspecto emocional durante toda su vida; 
este circuito, al completarse el proceso, se cierra a los dos años de vida; sin embargo, la expresión y control de las emociones se puede aprender después, pero siempre tendrá que partir de la base neuronal que se forma hasta la edad citada.

También se hace necesario conocer cómo reaccionan y cuáles son los componentes químicos que intervienen en las emociones, éstos son enviados desde algunos órganos como la médula, las glándulas suprarrenales, los rińones y la protuberancia anular, hacia las diferentes partes del organismo para influir en nuestra conducta. Estos productos circulan por el organismo y con frecuencia lo dominan; por eso cuando se produce una emoción, es difícil para el córtex desconectarse de ella (6).

Los componentes químicos se denominan péptidos y son entre otros: la serotonina, neurotransmisor que se almacena en determinadas células del cerebro, activa parte del córtex cerebral, estimula la memoria y actúa sobre el centro emocional del cerebro, lugar donde se generan y modulan los sentimientos; desempeńa un papel relevante en la regulación del comportamiento humano y es clave en nuestro bienestar, especialmente en todos los aspectos relacionados con la ansiedad, la depresión, el sueńo, los estados de ánimo, la sexualidad; además, controla y regula las funciones neuroendocrinas y cognitivas entre otros aspectos (9).

Si los niveles de serotonina son bajos inciden en la depresión, en la agresión impulsiva, la ira explosiva, el alcoholismo, la violencia y el suicidio. Por el contrario, si los niveles de serotonina son altos, puede ocasionar alucinaciones, baja confianza en sí mismos, agresión reprimida, alteración en la presión arterial y ritmo cardiaco acelerado (6). Si los niveles son adecuados nos sentimos satisfechos, calmados y felices. El aminoácido esencial que se requiere para la producción de la serotonina es el triptófano, el cual se encuentra en alimentos ricos en carbohidratos, harinas, arroz; así mismo, para favorecer la síntesis de esta sustancia, se requiere hacer ejercicio de forma vigorosa, realizar algo novedoso, practicar alguna técnica de relajación, entre otros aspectos.

Las endorfinas pertenecen a un grupo de proteínas que se producen en el cerebro a nivel de la glándula hipófisis y tienen características similares a las drogas opiáceas, con propiedades analgésicas y placenteras. Son liberadas y distribuidas a través de todo el sistema nervioso central para mantener el equilibrio, en respuesta al dolor o al esfuerzo sostenido; también están conectadas con los centros del placer del cerebro, es decir, cuando existe mayor secreción de endorfinas la persona se siente contenta, placentera y eufórica. Al favorecer la producción de endorfinas, se mejora el estado de ánimo y la sensación de bienestar; para aumentar la producción de ésta se debe, entre otros aspectos, realizar tareas gratas, ejercicio físico, demostraciones de afecto, masajes, caricias, risa, baile, relajación y contacto con la naturaleza.

La noradrenalina, es un neurotransmisor que mantiene activo al cerebro humano, es decir, hace estar alerta y tener claridad de conocimientos; ésta se activa cuando una información sensorial llega a la amígdala (en el cerebro), la cual produce la secreción de noradrenalina, hormona responsable del estado de alerta cerebral, y alcanza su punto máximo en las primeras horas de la mañana.

Una concentración baja de noradrenalina causa infraexcitación, búsqueda de emociones, asunción de riesgos y mayor probabilidad de violencia; la concentración alta origina sobreexcitación, pulso rápido, mayor probabilidad de violencia impulsiva, estrés, taquicardia, sudoración, ansiedad, y depresión (6).

La adrenalina, es una hormona secretada por las glándulas suprarrenales, hace que reaccionemos ante una situación de emergencia o alto riesgo; acelera la hiperactividad del sistema nervioso para responder a ciertas situaciones de alarma: acelera el ritmo cardiaco; aumenta la respiración para oxigenar la sangre; dilata las pupilas; aumenta la presión sanguínea, detiene momentáneamente los movimientos intestinales; acude a las reservas de glucógeno para proveer a los músculos de combustible; produce estados de euforia, de máxima energía, de capacidad de acción y de relax por la liberación de endorfinas. La adrenalina permite reaccionar en situaciones de estrés; la producción elevada de ésta conduce a la fatiga, la falta de atención, el insomnio y la ansiedad, entre otras; los niveles bajos causan decaimiento y depresión. 
En este orden de ideas, también es imprescindible tener en cuenta los descubrimientos realizados por Goleman (7) en torno de los centros emocionales del cerebro, que están conectados con el sistema inmunológico, lo cual ayuda a fortalecer el cuerpo contra las diferentes enfermedades; igualmente, las emociones actúan como impulsos y cada emoción se encarga de preparar el cuerpo para dar respuestas fisiológicas determinadas ante diferentes situaciones de la vida, por ejemplo: cuando la persona por algún disgusto siente ira la manifiesta con agresividad, esto ocurre por el aumento de la adrenalina; el temor se manifiesta en mayor concentración de sangre en los músculos, lo cual facilita la huida; ante la felicidad, se inhiben los sentimientos negativos y se aumentan los niveles de energía; cuando se siente amor, el organismo se relaja y hay un estado general de calma y placidez; la tristeza conlleva una disminución en los niveles de endorfinas, lo cual inhibe el sistema inmunológico.

Candace Pert, investigador de las emociones y cotizado neurocientífico citado por Jensen (6) sostiene que:

cuando las emociones se expresan [...]. Todos los sistemas se unen y forman un todo. Cuando las emociones se reprimen, o se niegan, no se permite su despliegue, nuestras vías de redes se bloquean, interrumpiendo el flujo de los componentes químicos unificadores vitales, que nos hacen sentirnos bien y que dirigen tanto nuestra biología como nuestra conducta.

De acuerdo con lo anterior, se sugiere que los docentes, luego de conocer la función que ejercen las emociones y sus componentes químicos en el comportamiento del cerebro, implementen técnicas dinámicas con sus estudiantes (gimnasia cerebral), realicen cambios de lugar, manejo de movimiento y posturas nuevas, así como ambientación del aula e incentivos para que consuman alimentos ricos en carbohidratos antes de iniciar cada período de clase, lo cual contribuye a elevar el nivel de serotonina, endorfinas y adrenalina, con el fin de establecer un equilibrio emocional que les permita liberarse del estrés, las tensiones, la angustia, la desconcentración y la desmotivación, entre otras dificultades inhibidoras del aprendizaje.
De igual modo, se requiere tener en cuenta que las emociones no sólo nos ayudan a tomar más decisiones con rapidez, sino a tomar decisiones de mejor calidad basadas en un valor; por ello, un exceso o una carencia de emoción es algo contraproducente, puesto que éstas son una parte importante de la vida; cuando se suprimen las emociones o se expresan de modos inadecuados se tienen problemas de disciplina y de aprendizaje; por esta razón, los docentes deben estimular las emociones productivas.

\section{La inteligencia emocional}

El término inteligencia emocional fue utilizado por primera vez en 1990 por Peter Salovey (10), profesor de la Universidad de Harvard, y John Mayer (10), profesor de la Universidad de New Hampshire, los cuales definen la inteligencia emocional como la capacidad de controlar y regular las emociones de uno mismo para resolver y enfrentar genuinos problemas de la vida diaria de manera pacífica, obteniendo un bienestar para sí mismo y para los demás; es también guía capaz de equilibrar el pensamiento y la acción.

Por su parte, Goleman (7) toma como base el estudio de Salovey y Mayer(10) definiendo la inteligencia emocional como un importante factor de éxito, y básicamente consiste en la capacidad "aprensible" para conocer, controlar e inducir emociones y estados de ánimo, tanto en uno mismo como en los demás, es una meta-habilidad que determina el grado de destreza que podemos conseguir en el dominio de nuestras otras facultades. Asimismo, la concibe como la capacidad para leer los sentimientos, controlar los impulsos, razonar, conservar la tranquilidad, ser optimistas cuando se trata de confrontar ciertas pruebas y mantenerse a la escucha del otro.

A su vez, a principios de la década pasada Salovey y Mayer (10), en relación con la inteligencia emocional propusieron la siguiente definición: la inteligencia emocional relaciona la habilidad para percibir con precisión, valorar y expresar emociones; relaciona también la habilidad para acceder y/o generar sentimientos cuando facilitan el pensamiento, también la habilidad para entender la emoción, el conocimiento emocional y la habilidad para regular emociones que promuevan el crecimiento intelectual.

Sobre la base de lo expuesto, se deduce que la inteligencia emocional interactúa con la cognitiva en 
los procesos de aprendizaje y en la vida cotidiana; no es posible excluir el aspecto afectivo y emocional en la formación de la persona, en las actividades laborales, en la convivencia y específicamente en las relaciones interpersonales, puesto que desde el punto de vista de los logros personales, la inteligencia emocional contribuye a exaltar los sentimientos y acentuar las actitudes cuando se trata de tomar decisiones cruciales, de resolver problemas o conflictos de diversa índole, de interactuar con los demás en diferentes escenarios donde la empatía es el ingrediente indispensable para el buen entendimiento, y donde es necesario actuar con respeto a la diferencia, a tener en cuenta el punto de vista de los otros, favoreciendo el debate sobre dilemas morales o sobre casos que exijan decisiones de carácter ético. Desde esta perspectiva se advierte que no sólo concurre la inteligencia cognitiva, sino también la emocional sobre todo cuando hay un equilibrio en la personalidad.

En el tema enunciado autores como Carlos Jiménez Vélez (11) hace énfasis en la influencia de la música en el aprendizaje de las personas y en el desarrollo de la inteligencia emocional, principalmente la clásica del estilo barroco. Coincide en el tema mencionado otro autor, Adrián Olander (12) al referirse a la relación música-funcionamiento del cerebro,en la manera como influye en los procesos emocionales. Por su parte Brackett (13) y la Revista Investigación y Ciencia (14) aluden a cómo se produce la intervención música-cerebro-emoción; señalan las competencias medibles de la inteligencia emocional en relación con la personalidad.

Otro especialista del tema, Evans (15) se refiere a la ciencia de los sentimientos en el campo emocional, mientras que Gil Olarte, Palomera y Brackett ya mencionado (13) hacen énfasis en la articulación inteligencia emocional y competencia social de los estudiantes. Cooper y Sawab (16) subrayan la importancia de la inteligencia emocional como componente en el proceso educativo, en tanto que Howe (17) expone la teoría del vínculo afectivo en el ámbito del trabajo social, como condición esencial para obtener un excelente desempeño.

De otra parte, Huxley (18) alude a la manera como se va conformando un mundo feliz en la vida de la persona gracias a diversos factores que contribuyen a ello, mientras que Niven (19) enuncia los cien secretos que hacen posible la felicidad de las personas; coincide con Ricard (20), quien presenta su discurso defensivo de la felicidad como factor indispensable en la vida del ser humano. Por su lado, Savater (21) se refiere al arte de vivir como campo de cultivo para las emociones humanas, al igual que Segal (22) haciendo énfasis en las incidencias de la inteligencia emocional; así mismo, Seligman (23) expone el tema de la felicidad auténtica, es decir, qué hace feliz a la persona; Shapiro (24) por su parte intenta explicar y definir en qué consiste la inteligencia emocional.

En el marco de los planteamientos y propuestas de los expertos estudiosos del cerebro emocional como Falkenberg (25), se asocia la inteligencia a la calidad de vida; desde la óptica de Fernández y Ruiz (26), la sonrisa puede ser una señal de felicidad; mientras que Furnham y Cheng (27) establecen una interesante relación entre personalidad y felicidad. Zubiría Samper (28) expone el tema de la felicidad desde una perspectiva psicológica positivista, en tanto que Bowlby (29) señala el vínculo afectivo presente en la persona. Cavalli Sforza (30) refuerza el tema de la felicidad ya enunciado por autores mencionados anteriormente y lo presenta como una ciencia obviamente concatenada a la emocionalidad.

En este orden de ideas Pinker (31) ilustra en torno del funcionamiento de la mente ligada al aspecto emotivo y Dueñas Buey (32) expone la importancia del componente emocional como reto en el proceso educativo discriminando los dos tipos de inteligencia: una que es fluida y se relaciona con la eficiencia mental no verbal, libre de influencias educativas y culturales como capacidad independiente de la experiencia; y otra, la inteligencia cristalizada que difiere de la anterior, la cual se relaciona con habilidades y conocimientos adquiridos pues para desarrollarse depende de la formación cultural y de la capacidad de uso de la información obtenida. Mientras que la primera inteligencia decrece con la edad, la segunda se incrementa con el tiempo y es identificada como conocimiento aprendido.

Bisquerra y Pérez (33) emiten sus planteamientos sobre las competencias emocionales que deben ser cultivadas con acierto, en tanto que Extremera y Fernández Berrocal (34) establecen nexos entre 
inteligencia emocional, calidad de las relaciones interpersonales y las manifestaciones empáticas de los estudiantes universitarios. De otra parte, Goleman (35) expone sobre las relaciones humanas como una ciencia nueva a la luz de la inteligencia social; Villanueva y otros autores (36) señalan los factores determinantes del desarrollo emocional y la competencia social. Otros investigadores que han abierto nuevos senderos de estudio y reflexión en esta temática como Elías, Tobías y Friedlander (37) se ocupan de relievar la importancia de la educación basada en la inteligencia emocional; por su parte, Sternberg (38) hace alusión a la inteligencia exitosa para resaltar aspectos novedosos del tema, mientras que Valles y otros (39) enfatizan en las aplicaciones educativas de la inteligencia emocional.

Bisquerra (40) en publicaciones que presentan el tema de la educación emocional, articula ésta con las competencias básicas para la vida; Berrocal (41) complementa los estudios al señalar aspectos claves de la afectividad enlazada a la inteligencia y Fernández unido a la experiencia investigativa de Berrocal así como Fernández Berrocal y Extremera (42) desarrollan su discurso en torno de la inteligencia emocional y la educación de las emociones desde el modelo de Mayer y Salovey (10).

Finalmente, Gilles Lipovetsky (43) señala que la consagración del presente no es tan evidente, pero sí la aparición de individuos preocupados por su felicidad personal y con ambiciones limitadas; afirma, además, que las sociedades hipermodernas del siglo XXI buscan una nueva jerarquía de valores así como una nueva forma de relacionarse con los objetos y el tiempo, con nosotros mismos y con las personas para, de este modo, encontrar la felicidad individual.

\section{Competencias emocionales}

Según Bisquerra(40) y Bisquerra y Pérez (33), se entiende por competencias emociónales un conjunto de conocimientos, capacidades, habilidades y actitudes necesarias para tomar conciencia, comprender, expresar y regular de forma apropiada los fenómenos emocionales. Como se puede observar, las competencias emocionales contribuyen a una mejor adaptación al contexto social y a afrontar de manera creativa los retos que se presentan en la cotidianidad; por ello, es un imperativo lógico que los docentes y estudiantes desarrollen estas competencias, para lograr un mejor aprendizaje, mejorar las relaciones inter/intrapersonales, lo que conlleva a elevar la calidad de vida y, por ende, ser más eficiente y eficaz en los diferentes escenarios donde tengan que desenvolverse.

Martín y Boeck (44), destacan que el mérito de los autores citados reside en haber identificado cinco capacidades integrantes de la competencia emocional: Reconocer las propias emociones: es decir, poder hacer una apreciación de las mismas; saber manejar las propias emociones: conlleva a conducir y controlar las reacciones emocionales sustituyendo lo congénito por formas sociales de comportamiento aprendidas; utilizar el potencial existente: el cociente intelectual (CI) alto por sí solo no es suficiente; para ser competente en los diferentes escenarios, es necesario tener desarrollada la inteligencia emocional; saber ponerse en el lugar de los demás: para ello, se debe escuchar y comprender los sentimientos del otro (empatía); y facilidad de establecer relaciones interpersonales: para poder tener buenas relaciones, es necesario saber resolver los conflictos personales y captar los estados de ánimo del otro.

Desde otra perspectiva se destacan cinco determinantes del desarrollo de la inteligencia emocional: Conciencia emocional, es decir, entender las propias fortalezas, los impulsos, estados de ánimo y, sobre todo, el propio sentimiento de vida, indispensable para el autocontrol. Autocontrol, es la habilidad para controlar nuestras emociones e impulsos, los estados de ánimo, permanecer tranquilos para afrontar los sentimientos de angustia, miedo y para recuperarse pronto de los sentimientos negativos. Motivación, es la capacidad de búsqueda constante y persistente del logro de los objetivos propuestos, haciendo frente a los problemas identificados. Empatía, es la habilidad para entender las necesidades, sentimientos, emociones y problemas de los demás, sentir con las otras personas., y habilidad social, que es la destreza para manejar las relaciones con los demás, sentir alegría de estar entre la gente, colaborar, ayudar, pertenecer a un grupo.

Los tres primeros determinantes dependen de la persona correspondiéndose con el propio yo en 
cuanto ser consciente de uno mismo, saber controlar los propios estados de ánimo y motivarse a sí mismo; en contraposición, los otros dos hacen referencia a las relaciones interpersonales configurando ambas la competencia social. En este orden de ideas, se observan dos enfoques relacionados con la inteligencia emocional: el referente al ámbito de la personalidad como conjunto integrado de disposiciones o tendencias de comportamiento tales como acertividad, optimismo, baja impulsividad y sociabilidad; y el que alude a la capacidad cognitiva vinculada al ámbito de la inteligencia (7).

Gallego y otros (45), plantean que existe una amplia serie de habilidades enunciadas por la teoría de la inteligencia emocional y son presentadas en tres ámbitos:

Habilidades emocionales que consisten en reconocer los propios sentimientos, identificarlos y expresarlos ante situaciones cotidianas, lo cual significa tener habilidad personal para poner los sentimientos en palabras con el fin de ser comprendido; controlar los sentimientos y evaluar su intensidad; tener conciencia en el momento de tomar una decisión, si ésta se halla determinada por los pensamientos o los sentimientos; aprender a controlar las emociones, teniendo en cuenta lo subyacente a un sentimiento: aprender formas diferentes de controlar los propios sentimientos.

Habilidades cognitivas mediante las cuales se comprenden los sentimientos ajenos y se respetan las diferencias individuales; se aprende a leer e interpretar los indicadores sociales; asumir la responsabilidad de las propias decisiones y acciones; tener en consideración las consecuencias de diferentes alternativas posibles; dividir en fases la toma de decisiones y de resolución de problemas; aprender a reconocer las propias debilidades y fortalezas; conservar una actitud positiva ante la vida con un fuerte componente afectivo; cultivar esperanzas realistas de sí mismo; ser diestro en la cooperación, resolución de conflictos y negociación de compromisos; distinguir entre diversas situaciones en las cuales hay quienes son hostiles y otras en las que la hostilidad proviene de sí mismo; ante situaciones de conflicto, describir las mismas y cómo se hacen sentir, determinando las opciones de que se dispone para resolver el problema presentado y cuáles serían sus posibles consecuencias; tomar una decisión al respecto y llevarla a término.

Habilidades conductuales que ayudan a resistir las influencias negativas; escuchar a los demás; participar en grupos positivos para interactuar con los compañeros; responder positivamente a la crítica; comunicarse con los demás a través de otros canales no verbales como gestos, expresión facial y tono de voz, entre otros; es clave resaltar que estas competencias no son cualidades innatas, sino habilidades aprendidas, las cuales individualmente aportan una herramienta básica para potenciar la eficacia; la carencia de las aptitudes mencionadas anteriormente se denominan analfabetismo emocional.

De otra parte, como lo plantea Bisquerra (40), las competencias emocionales se pueden clasificar, así:

Conciencia emocional: capacidad para reconocer las propias emociones, sus efectos así como las de los demás. Dentro de esta categoría se pueden incluir los siguientes aspectos: toma de conciencia de las propias emociones, dar nombre a las emociones, comprensión de las emociones de los demás, tomar conciencia de la interacción entre emoción, cognición y comportamiento.

Regulación emocional: es la capacidad para manejar las emociones; tomar conciencia entre emoción, cognición y comportamiento; identificar estrategias de afrontamiento; y capacidad para autogenerarse emociones positivas. Las microcompetencias que la configuran son: expresión emocional apropiada, regulación de emociones y sentimientos, habilidades de afrontamiento, competencia para autogenerar emociones positivas.

Autonomía emocional: está relacionada con la autogestión personal como la autoestima, responsabilidad, actitud positiva, y capacidad para analizar críticamente las normas sociales, entre otros aspectos. Las microcompetencias son autoestima, automotivación, autoeficacia emocional, responsabilidad, actitud positiva y resiliencia.

Competencia social: es la capacidad para mantener buenas relaciones con los demás. Las microcompetencias que incluye son el respeto por los demás, el dominio de las habilidades sociales básicas, la práctica de la comunicación receptiva, 
el comportamiento prosocial y cooperación, el compartir de las emociones, la asertividad, la prevención y solución de conflictos y la capacidad para gestionar situaciones emocionales.

Competencia para la vida y el bienestar: es la capacidad de adoptar comportamientos adecuados y garantes para afrontar con entereza los problemas que se presentan en los diferentes escenarios de la vida. Las microcompetencias propias son la fijación de objetivos adaptativos, la toma de decisiones, la ciudadanía activa, participativa, crítica, responsable, comprometida y equilibrada propendiendo al bienestar emocional.

En el contexto anterior, se concluye que las competencias emocionales propuestas por los diferentes autores incluyen prácticamente las mismas habilidades, lo cual permite deducir que todos concuerdan con unas competencias básicas que debe desarrollar el individuo para tener éxito en los diferentes ámbitos en que debe actuar.

Así mismo, cabe destacar que uno de los aportes que más ha incidido en el desarrollo de la inteligencia y de la inteligencia emocional en particular, ha sido la teoría de las inteligencias múltiples de Gardner (46), siendo la inteligencia inter/intrapersonal la que permite a la persona entender a los demás y comprenderse a sí mismo.

De otra parte, se deduce que la inteligencia emocional da respuesta a una serie de necesidades presentes en la sociedad actual como son el estrés, la angustia, la ansiedad, la depresión, la violencia y la drogadicción, entre otros aspectos; por ello, es indispensable conocer el perfil emocional del individuo, cualquiera sea el ámbito de su desempeño, para orientar y modificar el comportamiento, lo cual le facilitará aprender a relacionarse con los demás, consigo mismo, conservar el equilibrio razónemoción, que es un indicio de madurez que incide en la convivencia pacífica y por consiguiente en el desarrollo cognitivo, como determinante esencial dirigido al logro de aprendizajes significativos y a fortalecer la autoestima para alcanzar la automotivación.

Las habilidades emocionales se hallan enlazadas de tal modo que, para una adecuada regulación emocional, es necesaria una buena comprensión emocional y a su vez, para una comprensión eficaz, se requiere de una adecuada percepción emocional. Es así que para el desarrollo de la inteligencia emocional, lo esencial es ejercitar las capacidades emocionales y convertirlas en un componente de las propias vivencias.

\section{La inteligencia emocional en el aula}

Los educadores deben conocer los procesos que ocurren en el cerebro para desarrollar estrategias curriculares y de aula, que contribuyan al fortalecimiento del cerebro racional y emocional. Si el desarrollo intelectual de los estudiantes es importante y se hace lo posible por mejorar su nivel de aprendizaje, conviene recordar que es necesario desarrollar el sistema emocional, pues la emoción es más fuerte que el pensamiento; por tanto, es pertinente preguntarnos qué están haciendo los educadores para potenciar las habilidades de madurez emocional de los estudiantes que les permita fortalecer su formación académica y elevar su nivel de aptitud social y emocional. Ello, induce a reflexionar sobre cómo las competencias emocionales y sociales necesarias para enfrentar de manera adecuada las emociones negativas y destructivas que se generan en un contexto competitivo, no sólo académico, sino laboral, no han sido desarrolladas en nuestra cultura debido a que siempre se ha creído que los aspectos emocionales y sociales de los estudiantes pertenecen a su intimidad y, por tanto, ellos son responsables de su propio desarrollo emocional.

De acuerdo con las nuevas propuestas y tendencias pedagógicas, es incuestionable que los docentes se comprometan a desarrollar su propia inteligencia emocional, es decir, ser capaces de expresar sus sentimientos en relación con sus estudiantes; demostrarles respeto, proponer estrategias de automotivación; controlar sus estados de ánimo negativos y manejar adecuadamente sus emociones; exteriorizar su empatía y la capacidad de escucha; cultivar el sentimiento de autoestima en forma estable; tratar convenientemente los conflictos que se producen en el aula y tener en cuenta que el tono utilizado en el trato a los estudiantes repercute en el desarrollo emocional de éstos, entre otros aspectos.

Por las anteriores razones, se deduce que la escuela y la universidad, mediante los estudiantes, 
docentes y tutores coadyuvan a la potenciación de la personalidad del individuo, a través de dimensiones como la cognitiva, afectiva, emocional, moral y lúdica, precisamente para lograr un sano equilibrio de mente, cuerpo, relaciones interpersonales en el individuo, dándole así la oportunidad de conocer y expresar las distintas posibilidades que posee en ese sentido. Esto es, el proceso de aprendizaje no debe referirse únicamente a los contenidos culturales y científicos, sino que debe ser la vía propicia para el desarrollo integral de la persona. En este ámbito conceptual, se considera que la educación no puede ser concebida como un simple proceso cognitivo, sino que debe desarrollar la inteligencia emocional, para configurar la personalidad total del individuo. (40)

Es de observar, que cuando el profesor sabe educar en el aspecto emocional, los estudiantes disfrutarán más el aprendizaje, demostrarán un optimo rendimiento académico en cuanto a creatividad, construcción de nuevos saberes e innovaciones, y estimularán con facilidad su propia autoestima, entre otros factores; de esta manera se origina una disminución de los problemas de aprendizaje y, de igual modo, de la agresividad en las actitudes.

Expertos como Extremera y Fernández-Berrocal (34), Montañez y Latorre (47), entre otros, señalan que existen cuatro áreas fundamentales en que la carencia de inteligencia emocional produce los problemas de conducta entre los estudiantes; la inteligencia emocional es necesaria para que tales áreas se desarrollen: inteligencia emocional y relaciones interpersonales; y bienestar psicológico; y rendimiento académico; y aparición de conductas disruptivas.

La inteligencia emocional y las relaciones interpersonales, son importantes por cuanto permiten ofrecer a quienes nos rodean una información adecuada acerca de nuestros estados emocionales, una vez que hayamos aprendido a canalizarlos correctamente; en este sentido, el hecho de ser emocionalmente inteligente procura mayor habilidad en la percepción, comprensión y manejo de las propias emociones, lo cual conlleva a extrapolar tales habilidades a las emociones ajenas. De otra parte, se ha demostrado que la inteligencia emocional y el bienestar psicológico ayuda al desarrollo de un adecuado equilibrio psicológico, así como a comprender mejor la mediación de ciertas variables emocionales de los estudiantes y su influencia en el equilibrio psicológico y en el bienestar personal.

A manera de ejemplo, se observa que los universitarios con mayor inteligencia emocional dan razón de un menor número de síntomas físicos, menos ansiedad social y depresión, mayor utilización de estrategias para solucionar problemas; cuando están expuestos a factores de estrés y amenaza, perciben estos estresores como menos riesgosos y sus niveles de cortisol y presión sanguínea disminuyen, también se recuperan de la mejor manera de estos problemas.

Por otro lado, la capacidad de desarrollar la inteligencia emocional incide de manera decisiva en la salud mental y en el rendimiento académico de los estudiantes, es decir, manejan el estrés y las dificultades emocionales, lo cual les permite adaptarse a los ambientes de trabajo de alta presión y responder de manera eficiente.

Desde el punto de vista de la inteligencia emocional y la aparición de conductas disruptivas, es de anotar que los bajos niveles de inteligencia emocional presentan mayores niveles de impulsividad así como deficientes habilidades interpersonales y sociales, lo cual favorece el desarrollo de variados comportamientos asociales como alejamiento del grupo, consumo de alucinógenos, drogas en general y alcohol, con el objeto de reparar los estados de ánimo negativos provocados por acontecimientos estresantes a los que están expuestos (48).

Según lo expuesto, es básico tener en cuenta que los conocimientos académicos se aprenden mejor si los estudiantes están motivados, controlan sus impulsos, son responsables y tienen iniciativa, entre otras características, es decir, si poseen inteligencia emocional; por ello, la educación y formación deben tener presente el desarrollo de estas competencias integrándolas en los currículos, cambiar el enfoque pedagógico en los actuales planes de estudio, y vincular el pensamiento con la realidad, teniendo en cuenta las diferentes facetas: historia, relaciones familiares, amorosas, amistosas, gustos, necesidades $y$ ambiciones entre otros aspectos.

Es relevante recalcar que no sólo debemos preocuparnos por desarrollar competencias cognitivas 
a nivel laboral, sino que es necesario tener en cuenta las estructuras que conforman la inteligencia emocional. Por ello, los docentes y estudiantes emocionalmente inteligentes se caracterizan por resaltar los aspectos positivos por encima de los negativos; valorar más los aciertos que los errores; más las cualidades que los defectos; más el esfuerzo que los resultados; buscar el equilibrio entre la tolerancia y la exigencia, es decir, poseer una actitud positiva. De igual modo, son capaces de reconocer las propias emociones y la afectividad, sobre todo aquellas que se consideran positivas y negativas; saber encontrar el equilibrio entre expresión y control; colocarse en el lugar del otro para captar sus emociones, así no las expresen en palabras, sino mediante la comunicación no verbal; demostrar capacidad de tomar decisiones adecuadas integrando lo racional y lo emocional; conservar la motivación, ilusión e interés; cultivar la autoestima y la confianza en sus propias capacidades para asumir los retos de la vida; tener la capacidad de superar las dificultades y frustraciones, así hayan sido negativas; poder integrar polaridades, es decir, lo cognitivo y lo emocional (hemisferio derecho-izquierdo).

Humberto Maturana (49) afirma que las emociones son disposiciones corporales dinámicas que están en la base de las acciones y que toda acción humana se funda en una emoción; es decir, no hay acción humana sin una emoción. Como se sabe, las emociones definen el espacio de acciones posibles de realizar, por ello éstas constituyen un aspecto relevante para facilitar el aprendizaje, emociones positivas o gratas permitirán la realización de acciones favorables para el aprendizaje, emociones negativas o no gratas no lo permitirán. En el caso de la interacción en el aula, las emociones que fundan las acciones de los estudiantes serán básicas para el curso que sigue su aprendizaje, al favorecer o limitar acciones de una cierta clase según sea la emoción que las sustente. Por ejemplo: un alumno enfermo, aburrido no realizará acciones favorables para el aprendizaje de las materias o contenidos tratados por el profesor en ese momento; por el contrario, un alumno motivado e interesado sí podrá hacerlo, favoreciendo así la construcción de su aprendizaje.

Desde esta perspectiva, hay que propender por la educación de las emociones de los estudiantes en el aula, teniendo presente que éstas son fenómenos multidimensionales que se caracterizan por cuatro elementos: cognitivo, fisiológico, funcional y expresivo. Aquellos van configurando unos esquemas emocionales basados en la experiencia y en el temperamento, los cuales constituyen la esencia de las diferencias emocionales; en tales esquemas se basan los estilos de pensamiento emocional que caracteriza a cada persona.

En este sentido, las dimensiones emocionales como principal componente de la inteligencia emocional son educables; de este modo, la acción educativa debe tener continuidad para que los estudiantes se apropien de ellas y las manifiesten en su relación dialógica con los demás; lo anterior con el objeto de integrar las dimensiones cognitiva, emocional y conductual. Las emociones dirigen la atención, crean significado y tienen sus propias vías de recuerdo, todo ello, se relaciona con el aprendizaje. Por ello, los docentes deben ayudar a que los estudiantes experimenten con claridad los sentimientos y puedan reparar los estados de ánimo negativos, lo cual incidirá en su rendimiento académico.

La educación de la inteligencia emocional es una necesidad imperativa que se justifica desde la finalidad de la educación, por cuanto ésta propende por el pleno desarrollo de la personalidad integral del estudiante; desde la acción educativa, puesto que la educación es un proceso representado por la relación interpersonal, la cual se caracteriza por fenómenos emocionales; a partir del autoconocimiento de la emocionalidad y afectividad; desde el fracaso escolar; para ello, se requiere abordar aspectos preventivos desde la educación emocional que faciliten afrontar el aprendizaje con herramientas que ayuden a superar la depresión y el descenso de la autoestima; a partir de las relaciones sociales, con el fin de enfrentar los conflictos que surgen de la interacción personal, debido a que son provocados por una inadecuada expresión de las emociones o un mal entendido en la interpretación de las mismas; de la salud emocional, para evitar las tensiones y controlar el estrés, prevenir la depresión y aprender a expresar tanto las propias emociones como interpretar las ajenas.

En la propuesta de Delors (5) en torno de los cuatro pilares fundamentales de la educación, ésta debe enfatizar en los dos últimos que son aprender 
a convivir y aprender a ser, puesto que son el eje del desarrollo personal y de la vida en sociedad, lo cual facilita la educación de las emociones y el desarrollo de las competencias propias de la inteligencia emocional.

\section{Estrategias para educar la inteligencia emocional}

La estrategia es un recurso metodológico que facilita las acciones a desarrollarse en el aula, para las cuales es preciso tomar en consideración los contenidos emocionales. La estrategia puede ser individual y /o grupal, ambas modalidades se complementan. En este sentido, algunas de las estrategias empleadas por los docentes pueden ser: dinámicas de motivación para que los estudiantes interactúen afectivamente con el componente temático; preguntas verbales y cuestionarios escritos, para llevar al estudiante a reflexionar sobre el impacto emocional de un determinado conocimiento o sobre el aporte de ese conocimiento; el uso de fotografías y escenas de la vida diaria suscitan en el estudiante la emergencia de las emociones, igualmente con base en material gráfico y en las propias experiencias del mismo, se facilita el análisis y la reflexión desde el punto de vista afectivo y emocional; la elaboración de relatos, y poesías creados especialmente para la actividad a desarrollar o seleccionados de obras literarias, son aspectos que inciden en el aspecto emocional; la propuesta de juegos de comunicación y expresión emocional; videos y películas que conduzcan de manera natural al análisis de las emociones de los personajes y de éstas en el estudiante como espectador; utilización de técnicas de juego de roles, donde el estudiante dramatiza y escenifica situaciones interpersonales que el docente estime de interés para la comprensión de los contenidos del programa; mensajes publicitarios como elementos de toma de conciencia, los cuales brindan la oportunidad de reflexionar en torno del contenido e impacto emocional de las imágenes; audiciones musicales como estímulo apropiado para producir estados emocionales, educar la sensibilidad, el gusto estético, educar en valores y desarrollar actitudes positivas; utilización del color y de la forma como estrategia para analizar lo que provoca su contemplación en el aspecto emocional; las artes en general, incluida la danza, proporcionan medios para expresar los sentimientos y las ideas creativas; esto hace que las experiencias de aprendizaje sean memorables; el uso de la imaginación para el descubrimiento de ideas nuevas es además un motivador por excelencia del aprendizaje y produce como emoción básica la curiosidad; el aprendizaje cooperativo (trabajo en equipo), es una estrategia educativa que indica cuándo los estudiantes aprenden juntos en parejas o en pequeños grupos, el aprendizaje es más eficiente, hay mayor receptividad, productividad y calidad logrando de este modo que los estudiantes se sientan más positivos, motivados y con un mayor grado de autoestima respecto de lo que aprenden; las dinámicas lúdicas que propenden por el desarrollo de la imaginación, la innovación, la creatividad y el ingenio de los estudiantes; esculturas vivientes es decir pedirle a los estudiantes que representen de manera física una idea, un concepto o alguna otra meta específica del aprendizaje; grupos cooperativos consiste en el uso de pequeños grupos que trabajan juntos en torno de un tema y lo abordan de diferentes maneras, trabajando cada estudiante en el tópico en el cual demuestre mayor competencia; juegos de mesa, estos son una manera entretenida para que los estudiantes aprendan en el contexto de un grupo social informal, ellos estarán concentrados en adquirir el aprendizaje centro del juego; participación con los compañeros, es decir, compartir con pares (estudiantes) la temática propuesta o reflexionar sobre alguna pregunta relacionada con la temática.

La interacción en el aula profesor-estudianteestudiante, constituye un modo de relación que tiene importantes consecuencias para la formación de los mismos; la percepción que éstos tienen de sus relaciones con los docentes es lo que mayor impacto tiene en ellos, no tanto el contenido de estudio, sino las vivencias respecto a sus interacciones con los distintos profesores. Igualmente, si deseamos revalorizar el papel de las emociones en nuestra cultura escolar, la formación de profesores es de gran importancia. Para que ello ocurra, es necesario conocer lo que sucede cotidianamente en la vida de los estudiantes; en este sentido vale la pena preguntarnos: ¿cuál es la percepción que ellos tienen de sus propias emociones en la interacción con sus profesores y pares?, ¿cuáles son las emociones que en ellos surgen con mayor frecuencia?, y ¿en qué contextos interaccionales ocurren? 
De otra parte, es relevante la formación del profesorado con el fin de capacitarlo para poner en práctica programas de desarrollo de competencias emocionales con los estudiantes; de igual modo, se requiere ofrecerle los medios necesarios con el fin de abordar esta nueva tarea educativa en la cual no siempre se encuentra preparado, debido a que la educación tradicional no le ha permitido explorar a fondo el desarrollo del cerebro y equilibrar, de esta manera, dos polos aparentemente opuestos como han sido, a lo largo del tiempo, la inteligencia cognitiva y la inteligencia emocional. En este sentido, es dable tener en cuenta las propuestas que guían el comportamiento emocional con el fin de aprender más sobre el desarrollo de la inteligencia emocional y la manera como se puede implementar este nuevo conocimiento en el aula de clase. (50)

Finalmente, es prioridad reforzar el desarrollo del cerebro límbico de los estudiantes, puesto que es el encargado del desarrollo de la inteligencia emocional. Si la persona es emocionalmente inteligente sabe manejar sus emociones de una forma adecuada, en el alcance de su propio bienestar y establecerá relaciones más exitosas con otras personas.

\section{Referencias}

1. Sperry, R. Lateral specializatión of cerebral function in the surgically separated hemispheres. En: F. J. McGuigan The Psycolophi-sioly of the thinking. New York: Academic Press; 1973.

2. Mclean, P. The triune brain evolution. New York: Plenun Press; 1990.

3. Herrmann, N. The creative brain. New York: Brain books; 1993.

4. Velásquez, Calle, Remolina. El cerebro: un mundo de posibilidades para el aprendizaje. Bogotá: Imprenta Nacional; 2006.

5. Delors, J..La educación encierra un tesoro. Bogotá: Santillana; 1996.

6. Jensen, E. Cerebro y aprendizaje. Competencias e implicaciones educativas. Madrid: Narcea; 2004.

7. Goleman, D.. Inteligencia emocional. Barcelona: Paidos; 1995.

8. Punset, E. Porqué somos lo que somos. Espańa: Litografía Rosés; 2010

9. Jiménez, C y Robledo, J.. La neuropedagogía y los comportamientos violentos. Bogotá: Magisterio; 2010.

10. Salovey, P., y Mayer, J. Practicar un estilo de afrontamiento inteligente: la inteligencia emocional y el proceso de afrontamiento. Acapulco; 1997.

11. Jiménez Vélez, C. Neuropedagogía. La música y el aprendizaje. 2011. Disponible en: www.geocities.com/ludicopei/musicayaprendizaje.htm

12. Olender, Adrián. Neuropedagogía: música y cerebro. Disponible en www. luciernaga-clap.com.ar/articulosrevistas/28 musicaycerebro.htm

13. Brackett, M. A. Convergencia, discriminación e incremento de la validez de competencias medibles de la inteligencia emocional. Personalidad y psicología social. Boletín 29. 2006.

14. Revista Investigación y Ciencia. Música, cerebro y emoción. Harvard University the Institute for music. Brain Science. Disponible en www. articulosrevistas $/ 28$

15. Evans, D. Emoción. La ciencia del sentimiento. Madrid: Taurus, 2002.
16. Cooper, R.K. y Sawab, A. La inteligencia emocional. Barcelona: Norma. 1997.

17. Howe, D. La teoría del vínculo afectivo para la práctica del trabajo social. Barcelona: Paidós. 1995.

18. Huxley, A. Un mundo feliz. Barcelona: Planeta. 1995.

19. Niven, D. Los cien secretos de la gente feliz. Bogotá: Norma. 2003.

20. Ricard, M. En defensa de la felicidad. Siglo XXI. Barcelona: Ediciones Urano S.A.

21. Savater, F. El arte de vivir. Barcelona: Planeta. 1997.

22. Segal, J. Su inteligencia emocional. Barcelona: Grijalbo. 1997.

23. Seligman, M. La auténtica felicidad. Barcelona: Ed. B. S. A. 2003.

24. Shapiro, L. E. Qué es la inteligencia emocional. Buenos Aires: Javier Vergara Editores. 1997.

25. Falkenberg, A. Calidad de vida. Journal of socio - economics. 1998

26. Fernández- Dols, J. y M. Ruiz Belda. Are smiles a sign of happiness. Es la sonrisa una señal de felicidad? Journal of personality and social psychology.1995.

27. Furnham, A. y H. Cheng. Personalidad y felicidad. Psychological reports. 1997.

28. Zubiría Samper, Miguel de. Psicología de la felicidad. Fundamentos de psicología positiva. Bogotá: FIPC. 2007.

29. Bowlby, J. El vínculo afectivo. Barcelona: Paidós. 1990.

30. Cavalli Sforza, Ll. y Cavalli Sforza, F. La ciencia de la felicidad. Barcelona: Grijalbo Mondadori. 2001.

31. Pinker, S. Cómo funciona la mente. Barcelona: Edición Destino. 2001.

32. Dueńas Buey, M. L. Importancia de la inteligencia emocional: un nuevo reto para la orientación educativa. Madrid: Universidad Nacional de Educación a Distancia. 2002.

33. Bisquerra, R. y Pérez, N. Las competencias emocionales. Revista de Educación XXL, 10. 2007.

34. Extremera, N. y Fernández Berrocal, P. Inteligencia emocional, calidad de las relaciones interpersonales y empatía en estudiantes universitarios. Clínica y salud, 15. 2004.

35. Goleman, D. Inteligencia social. La nueva ciencia de las relaciones humanas. Barcelona: Kairós. 1996.

36. Villanueva, L., Clemente, R. y Adrián, J. Desarrollo emocional y competencia social. REME, 7. 1997.

37. Elías, M., Tobías, S. y Friedlander, B. Educar con inteligencia emocional. Barcelona : Plaza y Janés. 1997.

38. Sternberg, R. La inteligencia exitosa. Barcelona: Paidós. 1997.

39. Vallés, A. y Vallés, C. Inteligencia emocional: aplicaciones educativas. Madrid: Ed. EOS. 2000.

40. Bisquerra, R. La educación emocional y competencias básicas para la vida. Revista de Investigación Educativa, vol. 21. 2005.

41. Fernández Berrocal, P. Corazones inteligentes. Barcelona: Kairós. 2002.

42. Fernández Berrocal, P. y Extremera. La inteligencia emocional y la educación de las emociones desde el modelo de Mayer y Salovey. Revista Interuniversitaria de formación del profesorado. Vol. 19 No. 3. 2005.

43. Lipovetsky. Los tiempos hipermodernos. Barcelona: Anagrama. 2006.

44. Martín, D y Boeck, K. Qué es la inteligencia emocional. Madrid: Ibérica grafics; 2000.

45. Gallego, R.Competencias cognoscitivas, un enfoque epistemológico, pedagógico y didáctico. Bogotá: Corporativa Editorial Magisterio; 1999.

46. Gardner, H. Inteligencias múltiples. La teoría en la práctica. Barcelona: Paidós; 1983.

47. Montańez, J. y Latorre, J. ¿¿Es la inteligencia emocional una cuestión de género? Socialización de las competencias emocionales en hombres y mujeres y sus implicaciones. España: Universidad de Málaga; 2008.

48. Álvarez, M. y Bisquerra, R.. Manual de orientación y tutoría. Barcelona: Cisspraxis; 1996.

49. Maturana, Humberto. Las contribuciones de Humberto Maturana a las ciencias de la complejidad y a la Sicología Chile: Instituto de terapia cognitiva; 1992.

50. Fernández-Berrocal, P., y Mestre, J. Manual de inteligencia emocional. Barcelona: Kairós; 2007. 